\title{
Dilemma in stress fractures
}

\author{
Anil Agarwal • Divesh Gulati
}

Received: 27 June 2008 / Accepted: 28 June 2008 / Published online: 12 August 2008

(C) Springer-Verlag 2008

We read with interest the article by Fottner et al. [3], concerning stress fractures presenting as tumours, where the authors described pain as the first symptom as well as the index finding for their inclusion criteria. But it is worth mentioning that atypical presentations of stress fractures are known and pain may be preceded by swelling/fullness or other signs of inflammation $[1,5]$.

The article emphasises the detection of a fracture line either on MRI or CT to differentiate between a tumourous condition and a stress fracture. Cortical abnormalities or fatigue lines only appear in advanced stages of stress

Concerning the article by Fottner A, Baur-Melnyk A, Birkenmaier C, Jansson V, Dürr HR (2008) Stress fractures presenting as tumours: a retrospective analysis of 22 cases. Int Orthop. doi:10.1007/s00264007-0488-5.

A reply on this paper is available at doi:10.1007/s00264-008-637-5.

A. Agarwal

Department of Paediatric Orthopaedics, CNBC,

Geeta Colony, Delhi, India

D. Gulati

Department of Orthopaedics, UCMS and GTB Hospital,

Shahdara, Delhi, India

\section{A. Agarwal $(\square)$}

4/103, East End Apartments, Mayur Vihar Ph-I Ext., Delhi, India 110096

e-mail: rachna_anila@yahoo.co.in fractures (Fredericson's MR imaging classification of osseous stress injury; grade 4) and are not present in early grades 1-3 [4], where the diagnosis is primarily clinical. Moreover, as the authors have themselves mentioned, pathological fractures in tumour lesions do occur and in such cases the diagnostic dilemma deepens. Correlation to the clinical setting, sequential radiographs, and a careful study of the fracture characteristics (fracture line continuous with the cortex, extending into the intramedullary space, orientated perpendicular to the cortex and the major weightbearing trabeculae [2]) help avoid this pitfall.

\section{References}

1. Daffner RH, Martinez S, Gehweiler JA, Harrelson JM (1982) Stress fractures of proximal tibia in runners. Radiology 142:63-65

2. Deutsch AL, Coel MN, Mink JH (1997) Imaging of stress injuries to bone: radiography, scintigraphy, and MR imaging. Clin Sports Med 16:275-90

3. Fottner A, Baur-Melnyk A, Birkenmaier C, Jansson V, Dürr HR (2008) Stress fractures presenting as tumours: a retrospective analysis of 22 cases. Int Orthop. doi:10.1007/s00264-0070488-5

4. Fredericson M, Bergman G, Hoffman KL, Dillingham MS (1995) Tibial stress reaction in runners: correlation of clinical symptoms and scintigraphy with a new magnetic resonance imaging grading system. Am J Sports Med 23:472-481

5. Lam HS, Wong WC (1993) Stress fracture of tibia that simulates malignancy: a case report. J Hong Kong Med Assoc 45(4):302-304 